\section{Intraprocedural Rupture of Aneurysms: Not Necessarily a}

\section{Small Problem}

We read with great interest the article by van Rooij et $\mathrm{al}^{1}$ regarding the endovascular treatment of very small aneurysms $(<3 \mathrm{~mm})$. The conclusion of the study that coiling of very small aneurysms is more frequently complicated by intraprocedural rupture (IPR) is consistent with previous series and is technically understandable. ${ }^{2,3}$ However, conflicting data do exist from the 1010 patients in the Cerebral Aneurysm Rerupture After Treatment (CARAT) study of patients presenting with subarachnoid hemorrhage. ${ }^{4}$ In this large multicenter study, we were surprised not to find a significant association of very small aneurysms with IPR. In fact, rates of IPR were not increased whether size was dichotomized into $<3$ or $>3 \mathrm{~mm}$ or when size was evaluated as a continuous variable.

The present study also reported no increase in mortality/morbidity associated with IPR in patients treated endovascularly. This is in stark contrast with results from CARAT, in which coiled patients who experience IPR had a statistically significant $63 \%$ increase in morbidity/mortality associated with IPR. ${ }^{4}$ These varied results illustrate the limitations of retrospective data that has been collected to date on this important complication, and further highlight the need for prospective studies to better understand the causes and consequences of IPR.

\section{References}

1. van Rooij WJ, Keeren GJ, Peluso JP, et al. Clinical and angiographic results of coiling of 196 very small $(\leq 3 \mathrm{~mm})$ intracranial aneurysms. AJNR Am J Neuroradiol 2009;30:835-39

2. Lim YC, Kim BM, Shin YS, et al. Structural limitations of currently available microcatheters and coils for endovascular coiling of very small aneurysms. Neuroradiology 2008;50:423-27

3. Nguyen TN, Raymond J, Guilbert F, et al. Association of endovascular therapy of very small ruptured aneurysms with higher rates of procedure-related rupture. J Neurosurg 2008;108:1088-92

4. Elijovich L, Higashida RT, Lawton MT, et al. Cerebral Aneurysm Rerupture After Treatment (CARAT) Investigators. Predictors and outcomes of intraprocedural rupture in patients treated for ruptured intracranial aneurysms: the CARAT study. Stroke 2008;39:1501-06

L. Elijovich

Hyman Newman Institute of Neurology and Neurosurgery Center for Endovascular Surgery at Roosevelt Hospital New York, NY

S.C. Johnston University of California San Francisco, Calif.

DOl 10.3174/ajnr.A1759 